\title{
Conhecimento populacional sobre prevenção e reconhecimento de sinais do câncer de pele: Um estudo transversal
}

Population knowledge about prevention and recognition of signs of skin cancer: A cross-section study

Conocimiento poblacional sobre pevención y reconocimiento de signos de câncer de piel: Estudio transversal

Recebido: 13/04/2021 | Revisado: 20/04/2021 | Aceito: 24/04/2021 | Publicado: 09/05/2021

\author{
Mariana Bussaneli Martins \\ ORCID: https://orcid.org/0000-0001-5034-212X \\ Universidade Cesumar, Brasil \\ E-mail: mariana_bmartins@hotmail.com \\ Ana Flávia Cury Ivantes \\ ORCID: https://orcid.org/0000-0003-1873-9818 \\ Universidade Cesumar, Brasil \\ E-mail: ivantes.ana@gmail.com \\ Karin Juliane Pelizzaro Rocha-Brito \\ ORCID: https://orcid.org/0000-0003-4499-314X \\ Universidade Cesumar, Brasil \\ E-mail: karinjuliane@gmail.com
}

\begin{abstract}
Resumo
O entendimento da população acerca do câncer de pele pode ser decisivo para seu desfecho clínico, já que o mau prognóstico está associado ao avanço da doença. O objetivo deste estudo foi verificar o conhecimento em ambiente universitário sobre as características e cuidados na prevenção do câncer de pele. Trata-se de um estudo transversal realizado em Maringá-PR, por questionário validado. Foram entrevistados 458 indivíduos, dos quais a maioria eram mulheres (62,01\%), variando entre estudantes das áreas de exatas, humanas ou biológicas e profissionais da instituição. Para análise, foram considerados fototipo de pele dos entrevistados e renda familiar. A metodologia foi baseada em um escore feito pela pontuação das questões, separando os entrevistados em grupos com baixo e alto conhecimento. Os dados obtidos evidenciaram que a maioria dos participantes apresentaram bom conhecimento relacionado à doença, a qual foi positivamente relacionada com a área de estudo dos participantes - saúde, e renda familiar - superior a 6 salários-mínimos. Contudo, as práticas preventivas mostraram-se pouco difundidas, mesmo nos grupos de bom conhecimento. Portanto, esse trabalho mostra a necessidade de ações informativas sobre as neoplasias cutâneas e sua prática pela população, a fim de ajudar na prevenção e na detecção precoce da doença.
\end{abstract}

Palavras-chave: Câncer de pele; Prevenção; Saúde coletiva.

\begin{abstract}
The population's knowledge of skin cancer can be decisive for its clinical outcome since the poor prognosis is related to the progress of the disease. The objective of the study was to verify the knowledge in this university environment about the characteristics and care in the prevention of skin cancer. This is a cross-sectional study carried out in Maringá-PR, using a validated questionnaire. 458 people were interviewed, most of whom were women (62.01\%), ranging from students in the exact, human, or biological fields and professionals at the institution. For analysis, the interviewees' skin phototype, and family income were considered. The methodology was based on a score made by scoring the questions, separating the interviewees into groups with low and high knowledge. The captured data show that most of the associates had good knowledge related to the disease, which was positively related to the study area of the participants - health, and family income - above 6 referenced. However, impending preventive practices are not widespread, even in groups with good knowledge. Therefore, this work shows the need for informational actions on skin neoplasms and their practice by the population, in order to help in the prevention and early detection of the disease.
\end{abstract}

Keywords: Skin cancer; Prevention; Public health.

\section{Resumen}

El conocimiento de la población sobre el cáncer de piel puede ser decisivo para su resultado clínico, ya que el mal pronóstico está asociado con la progresión de la enfermedad. El objetivo de este estudio fue verificar el conocimiento en el ámbito universitario sobre las características y cuidados en la prevención del cáncer de piel. Se trata de un 
estudio transversal realizado en Maringá-PR, utilizando un cuestionario validado. Se entrevistaron 458 personas, la mayoría mujeres $(62,01 \%)$, desde estudiantes del ámbito exacto, humano o biológico hasta profesionales de la institución. Para el análisis se consideró el fototipo de piel de los entrevistados y los ingresos familiares. La metodología se basó en una puntuación obtenida mediante la puntuación de las preguntas, separando a los entrevistados en grupos de bajo y alto conocimiento. Los datos obtenidos mostraron que la mayoría de los participantes tenían buenos conocimientos relacionados con la enfermedad, lo que se relacionó positivamente con el área de estudio de los participantes - salud e ingresos familiares - por encima de los 6 salarios mínimos. Sin embargo, las prácticas preventivas se han mostrado poco extendidas, incluso en grupos con buenos conocimientos. Por tanto, este trabajo muestra la necesidad de acciones informativas sobre las neoplasias cutáneas y su práctica por parte de la población, a fin de ayudar en la prevención y detección precoz de la enfermedad.

Palabras clave: Cáncer de piel; Prevención; Salud pública.

\section{Introdução}

O câncer é um conjunto de doenças caracterizado pelo crescimento anormal, rápido e incontrolado das células teciduais, que proliferam além de seus limites locais, e podem se estender para outros órgãos e tecidos em um processo denominado de metástase (World Health Organization [WHO], 2018). A Organização Mundial da Saúde (OMS) estimou que no ano de 2018 ocorreram 18 milhões de novos casos de câncer, sendo que cerca de 1 em cada 6 pessoas foram ao óbito por causas cancerígenas (WHO, 2018). No Brasil, a estimativa para cada ano do triênio 2020 - 2022 aponta a ocorrência de 625 mil casos novos de câncer, sendo o câncer de pele não melanoma o mais incidente (177 mil), seguido pelos cânceres de mama e próstata (66 mil cada), cólon e reto (41 mil cada), pulmão (30 mil) e estômago (21 mil) (Instituto Nacional do Câncer [INCA], 2019).

O câncer de pele é definido como a neoplasia que promove o crescimento desordenado das células da pele e, de acordo com a linhagem acometida, pode ser do tipo melanoma e não melanoma. O câncer de pele do tipo melanoma é a neoplasia cutânea maligna que atinge os melanócitos da camada basal da epiderme, transformando-se e expandindo-se para outras camadas, sejam elas mais profundas ou superficiais (Iranzo et al., 2015). Apesar de ser pouco prevalente no Brasil e no mundo, esse apresenta alta letalidade, com estimativa de cerca de 8.450 novos casos no país, sendo 4.200 em homens e 4.250 em mulheres, mas se diagnosticado e tratado precocemente apresenta elevada chance de cura (Instituto Nacional do Câncer [INCA], 2020).

Ainda, o melanoma cutâneo apresenta como principal fator de risco a radiação ultravioleta, por isso, países próximos à Linha do Equador, como o Brasil, apresentam elevadas chances de desenvolver a doença (Matheus \& Verri, 2015). Ademais, câmeras de bronzeamento artificial, histórico familiar ou individual de câncer de pele, ter pele e olhos claros, albinismo, imunodepressão por doenças ou uso de imunossupressores, exposição à fuligem, ao arsênico e seus compostos, ao alcatrão de carvão e aos óleos minerais e de xisto são outros fatores que também corroboram para a sua ocorrência (Castilho et al., 2010; Instituto Nacional do Câncer [INCA], 2018). Por fim, as características dessa neoplasia geralmente se apresentam como uma pinta escura, assimétrica, com bordas irregulares, maior que $6 \mathrm{~mm}$, de coloração variável e, geralmente, múltipla em uma mesma lesão com evolução em suas características, que podem acompanhar prurido e descamação (INCA, 2020).

No que lhe concerne, o câncer de pele do tipo não melanoma é a neoplasia benigna ou maligna que acomete as células epiteliais que não sejam os melanócitos. Ele pode ser classificado em Carcinoma Basocelular ou Epitelioma Basocelular, quando originado das células epiteliais imaturas da camada basal da epiderme que invadem os tecidos adjacentes, através de expansões digitiformes irregulares de suas células, e, em Carcinoma Espinocelular ou Epidermoide, quando se inicia na camada basal da epiderme em regiões que apresentam grande quantidade de queratina (Tovo et al., 2002). Esse é o tipo de câncer mais frequente no Brasil, correspondendo a 30\% de todos os tumores malignos registrados no país, com estimativa de 176.930 novos casos no Brasil, sendo 83.770 em homens e 93.160 em mulheres (Instituto Nacional do Câncer [INCA], 2020). 
Assim como no melanoma cutâneo, os mesmos fatores de risco podem resultar no câncer de pele do tipo não melanoma, porém a sua apresentação clínica é diferente. No Carcinoma Basocelular, as lesões podem apresentar especificidades morfológicas em nodular, ulcerada, superficial, esclerodermiforme e metatípica e, ainda evolução lenta (Tovo et al., 2002). No Carcinoma Epidermoide, por sua vez, as lesões podem ser descamativas, irregulares, verrucosas, com base eritematosa e, algumas vezes, ulceradas e de bordas elevadas, e que, por ocorrerem em regiões com grande quantidade de queratina, apresentam lesões de coloração avermelhada, conhecidas por Ceratose Actínica (Favalli et al., 2007). Em ambos os tipos, contudo, manchas pruriginosas, descamativas ou que sangram, assim como sinais ou pintas que alteram de tamanho, forma ou cor e feridas que não cicatrizam em 4 semanas são altamente sugestivas de neoplasias do tipo não melanoma (INCA, 2020).

Com base nisso, para a prevenção das neoplasias de pele é necessário o conhecimento da população acerca dos fatores de risco e a maneira de preveni-los, bem como a compreensão dessas, no que toca às principais manifestações clínicas da doença, favorecendo assim a procura médica mais rápida e possibilitando o diagnóstico precoce da doença e, consequentemente, um melhor prognóstico. Além disso, evitar a exposição solar, principalmente nos horários de radiação mais intensa (entre 10h e 16h), utilizar equipamentos de proteção contra a radiação solar, tais como óculos, bonés, chapéus, roupas térmicas, sombrinhas e guarda-sol, são medidas imprescindíveis para prevenir a ocorrência da doença (Sociedade Brasileira de Dermatologia [SBD], 2013). Ademais, independente da exposição solar ou não, os fotoprotetores solares devem ser sempre utilizados, sejam na forma tópica ou de aerossol. Um fotoprotetor eficiente é aquele que combate as radiações UVA e UVB e, para isso, a Sociedade Brasileira de Dermatologia (SBD) recomenda o uso de filtro solar com fator de proteção de no mínimo 30, devendo esse ser aplicado de 15 a 30 minutos antes da exposição ao Sol (se essa ocorrer), e reaplicado, em geral, regularmente a cada 2 ou 3 horas. A quantidade indicada varia conforme a área corporal, sendo descrita como a uma colher de chá nas regiões da cabeça, rosto e pescoço e, duas colheres de chá distribuídas nas demais regiões do corpo de maneira uniforme, de modo a não deixar nenhuma área desprotegida (SBD, 2013).

Apesar disso, poucos estudos na literatura avaliaram o conhecimento a respeito das manifestações clínicas, sinais e sintomas do câncer de pele. Assim, tendo em vista a ocorrência elevada das neoplasias de pele no país, o aumento vultoso nos índices de novos casos nos últimos anos e a vantagem do conhecimento das manifestações clínicas e fatores de risco, como forma de se obter a prevenção e até o diagnóstico precoce da doença, este estudo teve como objetivo compreender o conhecimento da população sobre as neoplasias de pele, tendo como foco a população em ambiente universitário da cidade de Maringá.

\section{Metodologia}

\subsection{Desenho do estudo}

O presente estudo tratou-se de uma pesquisa de campo de natureza observacional com objetivo exploratório e forma de abordagem quantitativa-analítica cujo intuito foi o de analisar o conhecimento de uma determinada população sobre a exposição aos fatores de risco, prevenção, manifestações clínicas, sinais e sintomas das neoplasias de pele. Para isso foi elaborado um questionário com base no artigo de, Kelati et al., (2017). Algumas alterações, entretanto, foram realizadas no questionário-base de modo a direcionar o estudo ao país-sede da pesquisa (Brasil), respeitando tanto a cultura e diversidades brasileiras, quanto o público-alvo do estudo, como mostra no Quadro 1 ao final desta seção metodologia. O levantamento bibliográfico, necessário para as etapas de elaboração do questionário e discussão dos dados, contou com as bases de dados PubMed Central, Cochrane BVS, Science Direct e SciELO, acessadas através dos descritores cânceres de pele, epidemiologia, fatores de risco, sintomas e manifestações clínicas, tanto na língua portuguesa, quanto inglesa. Para a seleção dos artigos foram considerados a data da publicação, a relevância e o impacto dos artigos publicados. Ademais, foram utilizados como fontes do 
estudo a Organização Mundial da Saúde (OMS), o Instituto Nacional do Câncer (INCA) e a Sociedade Brasileira de Dermatologia (SBD). O estudo respeitou as normas e diretrizes para a realização de pesquisas envolvendo os seres humanos, sendo, portanto, realizados após aprovação (CAAE: 02575218.4.0000.5539) pelo Comitê de Ética em Pesquisa com seres humanos (CEP) da Universidade Cesumar (UniCesumar).

\subsection{Elaboração e validação do questionário}

O questionário aplicado foi elaborado com base no artigo de Kelati, A. et al., (2017). O instrumento de pesquisa incluiu itens que foram divididos em 5 sessões: a) perfil demográfico do indivíduo - 6 itens; b) conhecimentos gerais de aspectos relacionados à pele e às neoplasias de pele -3 itens; c) conhecimento sobre a exposição ao Sol e proteção solar -4 itens; d) conhecimentos específicos relacionados às neoplasias de pele - 13 itens, e; e) engajamento relacionado às neoplasias de pele -5 itens. Em todas as sessões os itens foram objetivos, permitindo que o entrevistado escolhesse uma ou mais entre as assertivas propostas. Após a elaboração, o questionário foi aplicado aos procedimentos de validação de conteúdo e de aparência, que consistiram em uma análise criteriosa das dimensões e dos itens do instrumento por um painel de juízes, composto por especialistas na área de promoção à saúde e dermatologistas. A seleção dos juízes teve como critério eleger representantes que possuíssem experiências e vivência na temática da pesquisa. Para validação foram elaboradas planilhas contendo os itens dos instrumentos que foram avaliados e os critérios de avaliação estabelecidos foram: organização, objetividade, clareza, pertinência e conteúdo. Cada item foi avaliado de acordo com os cinco parâmetros anteriores, de forma que os juízes julgaram de 0 a 4 o nível de cada questão, considerando ' 0 ', no caso de o item não contemplar o critério e '4', se o item satisfizesse completamente o critério. Ao final do instrumento de avaliação, os juízes puderam, através de um espaço aberto a comentários e sugestões, recomendar itens necessários que, porventura, estivessem ausentes ou a eliminação de algum item que não fosse pertinente. Sendo assim, os juízes foram convidados pessoalmente a participarem desta etapa e foi dado um prazo inicial de 15 dias para as contribuições.

\subsection{Local da pesquisa e participantes}

A pesquisa foi realizada na sede da Universidade Cesumar (UniCesumar) na cidade de Maringá após o aceite do Comitê de Ética em Pesquisa (CEP-UniCesumar), conforme as diretrizes que regulamentam as pesquisas com seres humanos. A escolha dos participantes ocorreu por seleção aleatória, abordando tanto os colaboradores da instituição (zeladores, professores, secretários, etc.), quanto os acadêmicos das áreas da saúde, exatas ou humanas. A faixa etária avaliada variou entre 18 e 60 anos, o que permitiu inferir se e/ou quanto o nível socioeconômico e os diferentes segmentos de estudos interferem sobre os cuidados e conhecimentos acerca das neoplasias de pele. A participação efetiva ocorreu somente após a leitura e assinatura do Termo de Consentimento Livre e Esclarecido pelos participantes.

\subsection{Análise estatística}

Os dados coletados foram tabulados e analisados de forma minuciosa e ainda revisados posteriormente. Para o cálculo do escore de conhecimento de neoplasias de pele foram consideradas 10 questões do questionário (questões 13, 15, 16, 17, 18, 19, 20, 21, 23 e 26). Nesse sentido, considerando as questões que admitiram apenas uma resposta, foi atribuída a pontuação 1 para os entrevistados que apontaram a alternativa correta e 0 para os que apontaram outra alternativa ou não as responderam. Já para as questões com mais de uma alternativa, tendo em conta cada opção, a pontuação foi obtida pela proporção de itens marcados (ou não marcados) corretamente, sendo assim, a pontuação de tais itens também varia de 0 a 1 . Desse modo, o escore total de conhecimento sobre neoplasias de pele foi calculado pela soma das pontuações das 10 questões, sendo que o mesmo pode variar entre 0 e 10 pontos e os respondentes que obtiveram escores menores de 5 pontos foram classificados com 
conhecimento baixo a respeito das neoplasias de pele, enquanto aqueles que obtiveram 5 pontos ou mais foram classificados com alto conhecimento. Ainda foi realizada uma análise descritiva dos escores do conhecimento sobre neoplasias de pele, descrevendo-os pela média aritmética simples, desvio padrão, coeficiente de variação, mínimo e máximo. Posteriormente, com o intuito de investigar possíveis associações entre as características dos indivíduos com a variável que indica a classificação do conhecimento sobre neoplasias de pele, utilizou-se a regressão logística univariada, estimando como medida de efeito as odds ratios (razões de chances), com intervalo de confiança de 95\%. Quanto mais próximo de 1 for o valor calculado da odds ratio, menor é a diferença entre as chances da ocorrência do evento de interesse. Ainda, foi possível verificar a significância dessa diferença através do valor $\mathrm{p}$ obtido pelo procedimento. Todas as análises foram realizadas com o auxílio do ambiente estatístico R (R Development Core Team), versão 3.5.

\section{Quadro 1. Questionário de pesquisa de campo.}

Data de preenchimento do questionário: 11

Perfil demográfico

1) Sexo: Masculino ( ) Feminino ( )

2) Idade:

(a) 18-25 anos

(b) 26-31 anos

(c) 31-36 anos

(d) 37-42 anos

(e) $\quad 42-60$ anos

3) Estado Civil

(a) Solteiro(a)

(b) Casado(a)

(c) Com companheiro(a)

(d) Viúvo(a)

4) Nível Educacional

(a) Sem escolaridade

(b) Ensino fundamental ( $\left.1^{\circ} \mathrm{grau}\right)$ incompleto

(c) Ensino fundamental (1 $\left.1^{\circ} \mathrm{grau}\right)$ completo

(d) Ensino médio ( $2^{\circ}$ grau) incompleto

(e) Ensino médio ( $2^{\circ}$ grau) completo

(f) Superior incompleto

(g) Superior completo

(h) Mestrado ou doutorado

(i) Não sei informar

5) Profissão:

6) Somando a sua renda com a renda das pessoas que moram com você, quanto é, aproximadamente, a renda familiar mensal? (Salário mínimo atual: R\$ 954,00)

(a) Nenhuma renda

(b) Até 1 salário mínimo

(c) De 1 a 3 salários mínimos

(d) De 3 a 6 salários mínimos

(e) De 6 a 9 salários mínimos

(f) De 9 a 12 salários mínimos

(g) De 12 a 15 salários mínimos

(h) Mais de 15 salários mínimos

Caracterização do perfil do indivíduo em relação ao conhecimento geral de aspectos relacionados a pele e ao câncer de pele

7) Qual o seu fototipo de pele?

(a) Fototipo 1: Pele branca, quando se expõe ao sol sempre queima, nunca bronzeia, muito sensível ao sol;

(b) Fototipo 2: Pele branca, quando se expõe ao sol sempre queima, bronzeia muito pouco, sensível ao sol;

(c) Fototipo 3: Pele morena clara, quando se expõe ao sol queima moderadamente, bronzeia moderadamente, sensibilidade normal ao sol;

(d) Fototipo 4: Pele morena moderada, quando se expõe ao sol queima pouco, sempre bronzeia, sensibilidade normal ao sol;

(e) Fototipo 5: Pele morena escura, quando se expõe ao sol queima raramente, sempre bronzeia, pouco sensível ao sol;

(f) Fototipo 6: Pele negra, quando se expõe ao sol nunca se queima, totalmente pigmentada, insensível ao sol;

8) Você conhece ou conheceu alguém que tem/teve câncer de pele?

(a) $\quad \mathrm{Sim}$

(b) Não 


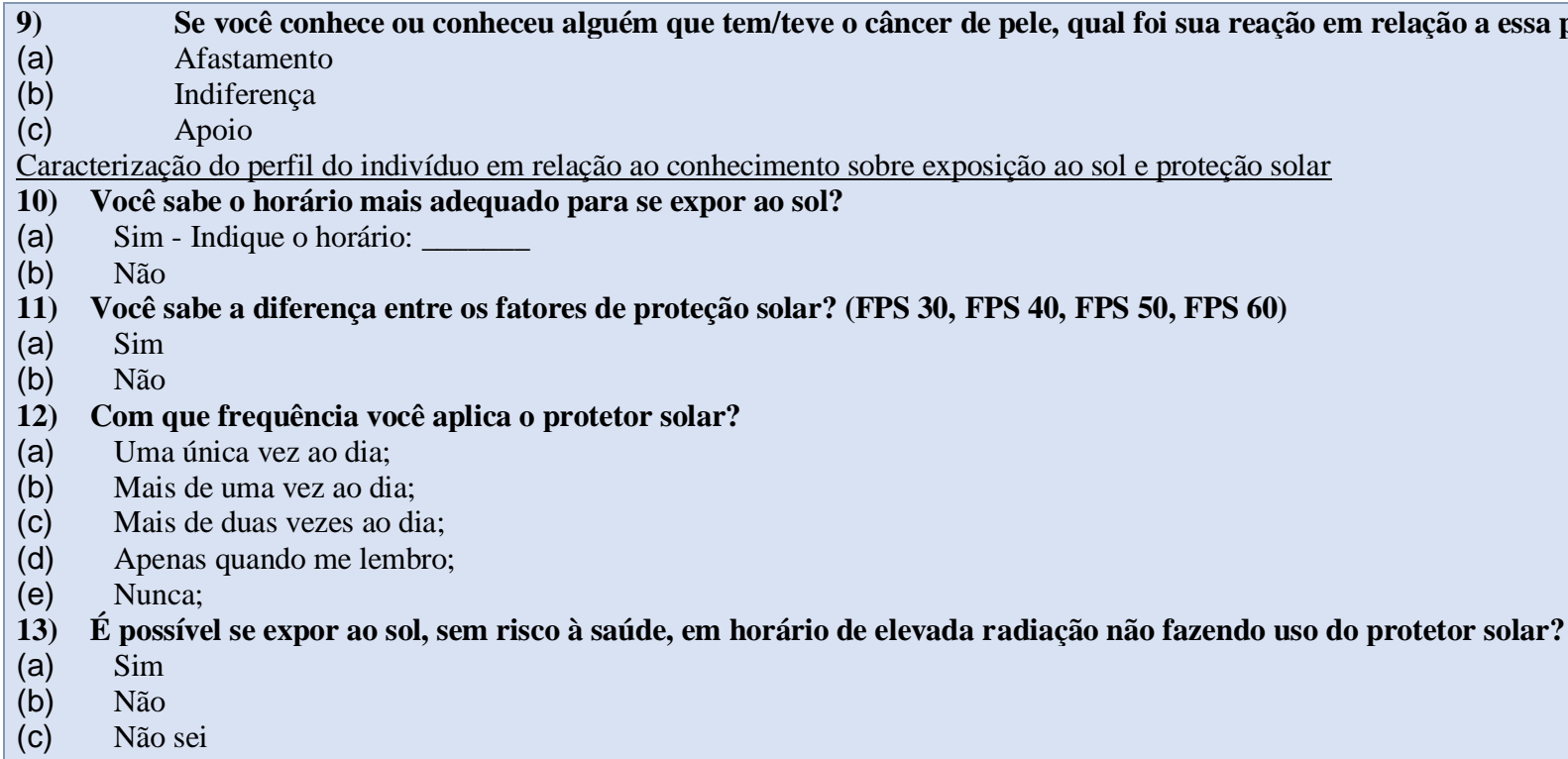

Caracterização do perfil do indivíduo em relação ao conhecimento específico relacionado ao câncer de pele

14) Você já ouviu falar sobre o Câncer de Pele?

(a) Sim

(b) Não

15) Você sabe se ter um câncer de pele é perigoso à saúde?

(a) $\quad \operatorname{Sim}$

(b) Não

(c) Não sei

16) Você acha que o câncer de pele pode matar?

(a) Sim

(b) Não

(c) Não sei

17) Quais dessas manifestações clínicas podem ser características do câncer de pele? (Assinale quantas alternativas você julgar necessário)

(a) Pápulas (elevações sólidas da pele, de pequeno tamanho, superficiais, bem delimitadas, com bordas facilmente percebidas quando se desliza o dedo sobre a lesão);

(b) Nódulos (lesões sólidas mais perceptíveis à palpação, de pequeno tamanho - geralmente de $1 \mathrm{~cm}$ a $3 \mathrm{~cm}$ );

(c) Tumores (lesões maiores do que os nódulos - mais de $3 \mathrm{~cm}$ - que podem ser malignas ou benignas);

(d) Úlceras (lesão aberta, com perda de conteúdo, da pele ou mucosa, causando desintegração);

(e) Bolhas com pus;

(f) Manchas pretas;

18) Quais desses sinais e sintomas podem ser característicos do câncer de pele? (Assinale quantas alternativas você julgar necessário)

(a) Aumento de tamanho;

(b) Mudança de cor;

(c) Resistência a tratamento usual (sem melhora);

(d) Coceira;

(e) Feridas que nunca cicatrizam;

(f) Sangramento fácil

19) Quais desses fatores de risco podem ocasionar um câncer de pele? (Assinale quantas alternativas você julgar necessário)

(a) Exposição à radiação (principalmente o sol);

(b) Cor da pele;

(c) Idade - Pessoas mais velhas apresentam maior risco de ter o câncer de pele;

(d) Idade - Pessoas mais jovens apresentam maior risco de ter o câncer de pele;

(e) Sexo - Homens apresentam maiores riscos de ter o câncer de pele;

(f) Sexo-Mulheres apresentam maiores riscos de ter câncer de pele;

(g) Fatores genéticos (família, história de câncer de pele);

(h) Produtos químicos;

(i) Infecção;

(j) Ter tido um câncer de pele;

(k) Tabagismo;

(I) Imunodepressão (ter queda na imunidade);

20) O câncer de pele pode envolver os tecidos de revestimento interno do corpo (mucosas)? Ex.: Boca, Intestino, Nasal, Estômago etc.

(a) $\quad$ Sim

(b) Não 
(c) Depende

(d) Não sei

21) O câncer de pele pode invadir outros tecidos/órgãos (metastatizar)?

(a) $\quad \mathrm{Sim}$

(b) Não

(c) Não sei

22) Caso a resposta anterior (questão 21) tenha sido sim, assinale a(as) alternativa(as) com os locais passíveis de sofrerem invasão (serem metastizados).

(Assinale quantas alternativas você julgar necessário)
(a) Pulmão
(b) Osso
(c) Fígado
(d) Trato Gastrointestinal
(e) Cérebro
(f) Linfonodos

23) Assinale quais itens devem ser avaliados para uma possível neoplasia de pele? (Assinale quantas alternativas você julgar necessário)

(a) Assimetria

(b) Borda mal delimitada

(c) Cor

(d) Diâmetro

(e) Evolução

(f) Presença de pelos junto com manchas

(g) Presença de pus ou sangue

(h) Elevação da pele

24) Você conhece ou já ouviu falar sobre o ABCDE do câncer de pele?

(a) Sim

(b) Não

25) Para quais tipos de câncer de pele o ABCDE se aplica?

(a) Melanoma

(b) Não melanoma (Carcinoma basocelular ou Carcinoma espinocelular)

(c) Os dois

Qual dessas imagens podem caracterizar uma neoplasia de pele? (Assinale quantas alternativas você julgar necessário)

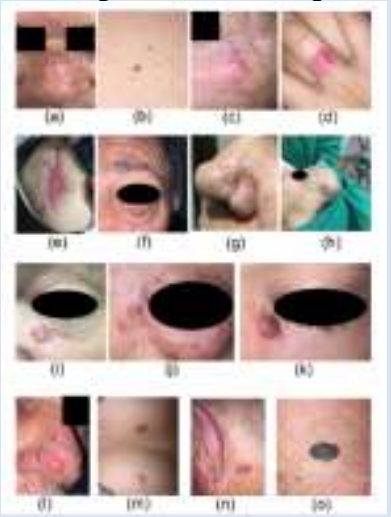

Caracterização do perfil do indivíduo em relação ao seu engajamento relacionado ao câncer de pele

\section{6) Você tem ou já teve uma lesão que achou suspeita?}

(a) Sim

(b) Não

27) Secê tem ou teve uma lesão que achou suspeita procurou serviço médico?

(a) $\quad \operatorname{Sim}$

(b) Não

28) Se você não procurou serviço médico, por quê?

(a) Não achou necessário

(b) Devido à demora do atendimento do SUS

(c) Medo de adquirir uma cicatriz

(d) Não quer perder o trabalho

(e) Acha que pode sarar sozinho

(f) Medo de ser um câncer

(g) Tentou usar creme/produtos que tinham em casa ou indicado por alguém

29) Você já teve ou tem o câncer de pele?

(a) $\quad \operatorname{Sim}$

(b) Não

(c) Não sei 
31. Se você tem ou teve câncer de pele qual serviço de saúde procurou?

(a) Sistema público de saúde

(b) Sistema privado de saúde

(c) Convênio (plano de saúde)

Fonte: Autores.

\section{Resultados}

\subsection{Validação do questionário elaborado}

Após análise dos especialistas, iniciou-se o processo de adequação do questionário. A fim de selecionar ou excluir os itens, foi elaborado um sistema no qual aqueles que tivessem pontuação inferior a 2 seriam excluídos. Assim, para cada critério (organização, objetividade, clareza, pertinência e conteúdo) foi determinada a média máxima de 4 pontos e as questões que apresentassem um desses itens com valor inferior a 2 pontos seria excluída. Como não houve itens com pontuação inferior à média estipulada, todas as questões inicialmente propostas continuaram a integrar os instrumentos. Apesar da não exclusão, as sugestões de modificações foram feitas, tanto para a organização, quanto na redação e melhor esclarecimento do enunciado dos itens.

\subsection{Características sociodemográficas dos participantes}

Foram considerados 458 entrevistados na análise, dos quais 62,01\% ( $n=284)$ eram mulheres e 37,99\% ( $n=174)$ eram homens, com predomínio de indivíduos na faixa etária de 18 - 25 anos $(68,53 \%)(\mathrm{n}=314)$, sendo em sua maioria solteiro $(76,32 \%)(\mathrm{n}=348)$, (Tabela 1$)$.

Com relação ao nível educacional, a maioria $(64,91 \%)(\mathrm{n}=296)$ apresentou Ensino Superior Incompleto, enquanto 20,18\% ( $\mathrm{n}=92$ ) possuía Ensino Superior Completo; 8,55\%, ( $\mathrm{n}=39$ ), Mestrado ou Doutorado; 5,92\% ( $\mathrm{n}=27)$, Ensino Médio Completo e 0,44\% ( $\mathrm{n}=2)$, Ensino Médio Incompleto. Quando perguntados sobre a renda, 29,18\% ( $\mathrm{n}=131)$ afirmaram apresentar entre 3 a 6 salários mínimos; 22,27\% (n=100), entre 1 a 3 salários mínimos; 12,92\% (n=58), entre 6 a 9 salários mínimos; 10,47\% ( $\mathrm{n}=47$ ), entre 9 a 12 salários mínimos; 9,35\% (n=42), entre 12 a 15 salários mínimos; 7,80\% (n=35), mais de 15 salários mínimos; 6,01\% (n=27), até 1 salário mínimo e, por fim, 2\% (n=9) não indicaram renda (Tabela 1). 
Tabela 1. Perfil sociodemográfico dos participantes da pesquisa.

Fonte: Dados da pesquisa.

\begin{tabular}{|c|c|c|}
\hline Características epidemiológicas & $\mathrm{N}=458$ & $\%$ \\
\hline \multicolumn{3}{|l|}{ Sexo } \\
\hline Masculino & 174 & 37,99 \\
\hline Feminino & 284 & 62,01 \\
\hline \multicolumn{3}{|l|}{ Idade } \\
\hline $18-25$ anos & 314 & 68,53 \\
\hline 26-31 anos & 64 & 13,94 \\
\hline 31-36 anos & 37 & 8,08 \\
\hline $37-42$ anos & 24 & 5,24 \\
\hline $42-60$ anos & 19 & 4,15 \\
\hline \multicolumn{3}{|l|}{ Estado civil } \\
\hline Solteiro & 348 & 76,32 \\
\hline Casado & 83 & 18,20 \\
\hline Com companheiro (a) & 24 & 5,26 \\
\hline Viúvo (a) & 1 & 0,22 \\
\hline \multicolumn{3}{|l|}{ Nível educacional } \\
\hline Sem escolaridade & 0 & 0 \\
\hline Ensino fundamental $\left(1^{\circ}\right.$ grau $)$ incompleto & 0 & 0 \\
\hline Ensino fundamental ( $1^{\circ}$ grau $)$ completo & 0 & 0 \\
\hline Ensino médio ( $2^{\circ}$ grau $)$ incompleto & 2 & 0,44 \\
\hline Ensino médio ( $2^{\circ}$ grau) completo & 27 & 5,92 \\
\hline Superior incompleto & 296 & 64,91 \\
\hline Superior completo & 92 & 20,18 \\
\hline Mestrado ou doutorado & 39 & 8,55 \\
\hline Não sei informar & 0 & 0 \\
\hline Não responderam & 2 & 0,77 \\
\hline \multicolumn{3}{|l|}{ Renda } \\
\hline Nenhuma renda & 9 & 2 \\
\hline Até 1 salário mínimo & 27 & 6 \\
\hline De 1 a 3 salários mínimos & 100 & 22,27 \\
\hline De 3 a 6 & 131 & 29,18 \\
\hline De 6 a 9 & 58 & 12,92 \\
\hline De 9 a 12 & 47 & 10,47 \\
\hline De 12 a 15 & 42 & 9,35 \\
\hline Mais de 15 salários mínimos & 35 & 7,80 \\
\hline Não responderam & 9 & 1,96 \\
\hline
\end{tabular}

\subsection{Caracterização do perfil do indivíduo em relação ao conhecimento geral de aspectos relacionados à pele, à exposição} ao sol e à proteção solar

Quando questionados a respeito do fototipo de pele, 38,65\% $(\mathrm{n}=177)$ dos indivíduos consideram-se do fototipo 2; 32,53\% (n=149), do Fototipo 3; 14,41\% (n=66), do Fototipo 4; 11,35\% (n=52), do Fototipo 1; 2,40\% (n=11), do Fototipo 5; $0,44 \%(\mathrm{n}=2)$, do Fototipo 6 e $0,22 \%(\mathrm{n}=1)$ dos participantes não responderam à pergunta. (Tabela 2).

Com relação ao conhecimento da fotoproteção, quando questionados sobre a frequência de aplicação do protetor solar, $33,84 \%(\mathrm{n}=155)$ do total de indivíduos disseram aplicar o protetor solar apenas quando se lembram, seguido por 27,73\% $(n=127)$ que afirmaram nunca utilizar o produto e 25,33\% $(n=116)$ que usam apenas uma vez ao dia. Ainda, 9,17\% ( $n=42)$ dos respondentes disseram que aplicam mais de uma vez ao dia e, por fim, apenas 3,93 $(\mathrm{n}=18)$ passam o protetor solar mais de duas vezes ao dia (Tabela 2).

Já quando os entrevistados foram perguntados sobre a possibilidade de se exporem ao sol, sem risco à saúde, em horários de elevada radiação não fazendo o uso do protetor solar, a maioria dos indivíduos, 64,85\%, (n=297), responderam não 
haver essa possibilidade de exposição sem risco. Contudo, 19,43\% (n=89) afirmaram não saber sobre essa chance e 15,72\% (n=72) asseguraram ser possível a exposição ao sol em horários de elevada radiação sem causar risco à saúde (Tabela 2).

Tabela 2. Caracterização do fototipo de pele, aplicação do protetor rolar e exposição ao sol.

\begin{tabular}{lll}
\hline Itens & $\mathbf{N}=\mathbf{4 5 8}$ & $\mathbf{\%}$ \\
\hline Fototipo de pele & 52 & 11,35 \\
Fototipo 1 & 177 & 38,65 \\
Fototipo 2 & 149 & 32,53 \\
Fototipo 3 & 66 & 14,41 \\
Fototipo 4 & 11 & 2,40 \\
Fototipo 5 & 2 & 0,44 \\
Fototipo 6 & 1 & 0,22 \\
Não responderam & & \\
Frequência de aplicação do protetor solar & 116 & 25,33 \\
Uma única vez ao dia & 42 & 9,17 \\
Mais de uma vez ao dia & 18 & 3,93 \\
Mais de duas vezes ao dia & 155 & 33,84 \\
Apenas quando me lembro & 127 & 27,73 \\
Nunca & & \\
É possível se expor ao sol, sem risco à saúde, em horário de elevada & & \\
radiação, não fazendo uso do protetor solar? & 72 & 15,72 \\
Sim & 297 & 64,85 \\
Não & 89 & 19,43 \\
Não sei & & \\
& &
\end{tabular}

Fonte: Dados da pesquisa.

\subsection{Caracterização do perfil do indivíduo em relação ao conhecimento específico relacionado ao câncer de pele}

A respeito do entendimento específico dos entrevistados sobre o câncer de pele, 98,69\% (n=452) afirmaram já terem ouvido falar sobre a neoplasia de pele, enquanto apenas $1,31 \%(\mathrm{n}=6)$ nunca ouviu falar de câncer de pele. Além disso, quando questionados sobre o perigo de se ter esse câncer, 93,89\% ( $\mathrm{n}=430)$ afirmaram que a neoplasia é perigosa, 4,80\% ( $\mathrm{n}=22)$ não souberam responder e 1,31\% ( $\mathrm{n}=6$ ) respondeu não ser perigoso. No que diz respeito a letalidade, $79,26 \%$ ( $\mathrm{n}=363$ ) afirmaram que a doença pode matar, enquanto $2,40 \%(\mathrm{n}=11)$ negaram que o câncer de pele pode levar à morte e $18,34 \%(\mathrm{n}=84)$ não souberam responder.

No que concerne às manifestações clínicas, que podem ser características do câncer de pele, 64,41\% (n=295) responderam que manchas pretas podem caracterizar a presença de uma neoplasia, enquanto 45,85\% (n=210) que as pápulas podem ser características da doença, 38,43\% $(\mathrm{n}=176)$ responderam sobre os tumores, 35,15\% $(\mathrm{n}=161)$ marcaram a presença de úlceras, $31,22 \%(\mathrm{n}=143)$ os nódulos, $17,03 \%(\mathrm{n}=78)$ as bolhas com pus e $1,53 \%(\mathrm{n}=7)$ não responderam à pergunta. No questionário havia a definição de cada uma dessas manifestações clínicas para que os entrevistados pudessem analisar de forma eficaz e satisfatória antes de marcar a alternativa.

Em relação aos sinais e sintomas que podem fazer-se presentes no câncer de pele, a mudança de cor da lesão (74,89\%) $(n=342)$, o aumento de tamanho da lesão $(63,32 \%)(n=290)$ e feridas que nunca cicatrizam $(60,92 \%)(n=279)$ foram os sinais mais respondidos pelos entrevistados. No entanto, resistência ao tratamento usual $(39,96)(n=183)$, coceira $(27,29 \%)(n=125)$ e sangramento fácil $(24,45 \%)(n=112)$, embora em menor proporção, também foram outros sinais e sintomas apontados.

No tocante aos fatores de risco para a neoplasia, 97,38\% $(n=446)$ dos entrevistados consideraram a exposição à radiação como uma das causas de câncer de pele; 72,05\% ( $\mathrm{n}=330)$, os fatores genéticos e 56,33\% ( $\mathrm{n}=258)$, a cor da pele. Ainda, 51,09\% $(\mathrm{n}=234)$ consideraram indivíduos mais velhos como aqueles mais propensos para adquirir esse câncer, 
contrapondo os 2,84\% ( $\mathrm{n}=13)$ dos respondentes que acharam os indivíduos mais jovens como mais suscetíveis. Além disso, 44,76\% ( $\mathrm{n}=205$ ) das pessoas questionadas afirmaram que já ter tido câncer de pele é considerado um fator de risco para adquirir novamente a neoplasia. Ainda, 46,94\% $(\mathrm{n}=215)$ presumiram sobre o uso de produtos químicos como um fator agravante; $31,44 \%(n=144)$, o tabagismo; 21,8\% ( $\mathrm{n}=100)$, a imunodepressão; 7,86\% ( $\mathrm{n}=36)$, os processos infecciosos e, por último, o sexo. Houve um número maior de entrevistados que consideraram que ser do sexo masculino $(10,44 \%)$ (n=46) é um fator de risco maior para adquirir a neoplasia de pele quando comparado ao sexo feminino $(9,39 \%)(n=43)$.

Sobre a relação entre as mucosas e o câncer de pele, 42,58\% (n=195) dos indivíduos não souberam responder a respeito. Já 37,55\% ( $\mathrm{n}=172)$ afirmaram que a neoplasia pode envolver os tecidos de revestimento interno do corpo, porém 7,64\% ( $\mathrm{n}=35)$ negaram essa possibilidade e 12,23\% ( $\mathrm{n}=56)$ afirmaram que o envolvimento de mucosas depende de outros fatores. Quanto à capacidade de causar metástase, 58,30\% ( $\mathrm{n}=267)$ dos entrevistados afirmaram haver a possibilidade; 3,93\% $(n=18)$, negaram e 37,77\% (n=173) não souberam responder à pergunta. Sobre os possíveis locais que são passíveis de sofrer metástase, apenas 267 entrevistados responderam à pergunta, evidenciando que o Pulmão $(49,44 \%)(\mathrm{n}=132)$, os Linfonodos $(44,19 \%)(n=118)$, Ossos $(40,45 \%)(n=108)$, Trato Gastrointestinal $(34,83 \%)(n=93)$, Fígado $(28,46 \%)(n=76)$ e Cérebro $(23,60 \%)(n=63)$ podem ser os órgãos acometidos em uma neoplasia de pele metastática.

Ademais, quando questionados sobre os itens que devem ser avaliados em uma possível neoplasia de pele, 71,83\% $(n=329)$ dos entrevistados responderam sobre a importância de avaliar a cor da lesão; 64,63\% (n=296), sua evolução; 54,15\% ( $\mathrm{n}=248)$, sua assimetria; 49,56\% ( $\mathrm{n}=227)$, as bordas mal delimitadas; 46,51\% ( $\mathrm{n}=213)$, o diâmetro da lesão; 36,24\% ( $\mathrm{n}=116)$, a projeção da lesão; 24,89\% ( $\mathrm{n}=114)$, a presença de pus ou sangue e, por fim, 13,76\% ( $\mathrm{n}=63)$ dos indivíduos responderam sobre a relevância de se avaliar a presença de pelos com manchas como característica que pode evidenciar o câncer de pele.

Já quando perguntados sobre o ABCDE do câncer de pele, enquanto 91,70\% ( $\mathrm{n}=420)$ nunca ouviram falar sobre a regra, 7,86\% (n=36) afirmaram já terem ouvido falar e 0,44\% (n=2) não responderam à pergunta. Dos que afirmaram conhecer sobre essa regra, 52,78\% $(\mathrm{n}=19)$ responderam que ela se aplica ao câncer de pele do tipo melanoma, e nenhum indivíduo respondeu que se aplica ao câncer de pele do tipo não melanoma. Ainda, 44,44\% ( $\mathrm{n}=16)$ dos participantes responderam que se aplica aos dois tipos e 2,78\% (n=1) não responderam à pergunta.

Referente às imagens que podem caracterizar o câncer de pele, 49,56\% ( $\mathrm{n}=227)$ dos entrevistados marcaram a Imagem A como característica de neoplasia; 16,81\% ( $\mathrm{n}=77)$, a Imagem B; 28,38\% ( $\mathrm{n}=130)$, a Imagem C; 10,04\% ( $\mathrm{n}=46)$, a Imagem D; 12,45\% (n=57), a Imagem E; 23,36\% ( $\mathrm{n}=107)$, a Imagem F; 18,34\% (n=84), a Imagem G; 38,43\% ( $\mathrm{n}=176)$, a Imagem H; 25,98\% ( $\mathrm{n}=119)$, a Imagem I; 37,99\% ( $\mathrm{n}=174)$, a Imagem J; 33,62\% ( $\mathrm{n}=154)$, a Imagem K; 32,31\% ( $\mathrm{n}=148)$, a Imagem L; 7,21\% ( $\mathrm{n}=33)$, a Imagem M; 39,30\% ( $\mathrm{n}=180)$, a Imagem $\mathrm{N} ; 38,86 \%(\mathrm{n}=178)$, a Imagem O e 9,61\% ( $\mathrm{n}=44)$ dos entrevistados não responderam à pergunta. As imagens que representam uma neoplasia de pele são as indicadas pelas letras A, C, F, G, I, J, K, L e N (Tabela 3). 
Tabela 3. Imagens usadas no questionário.

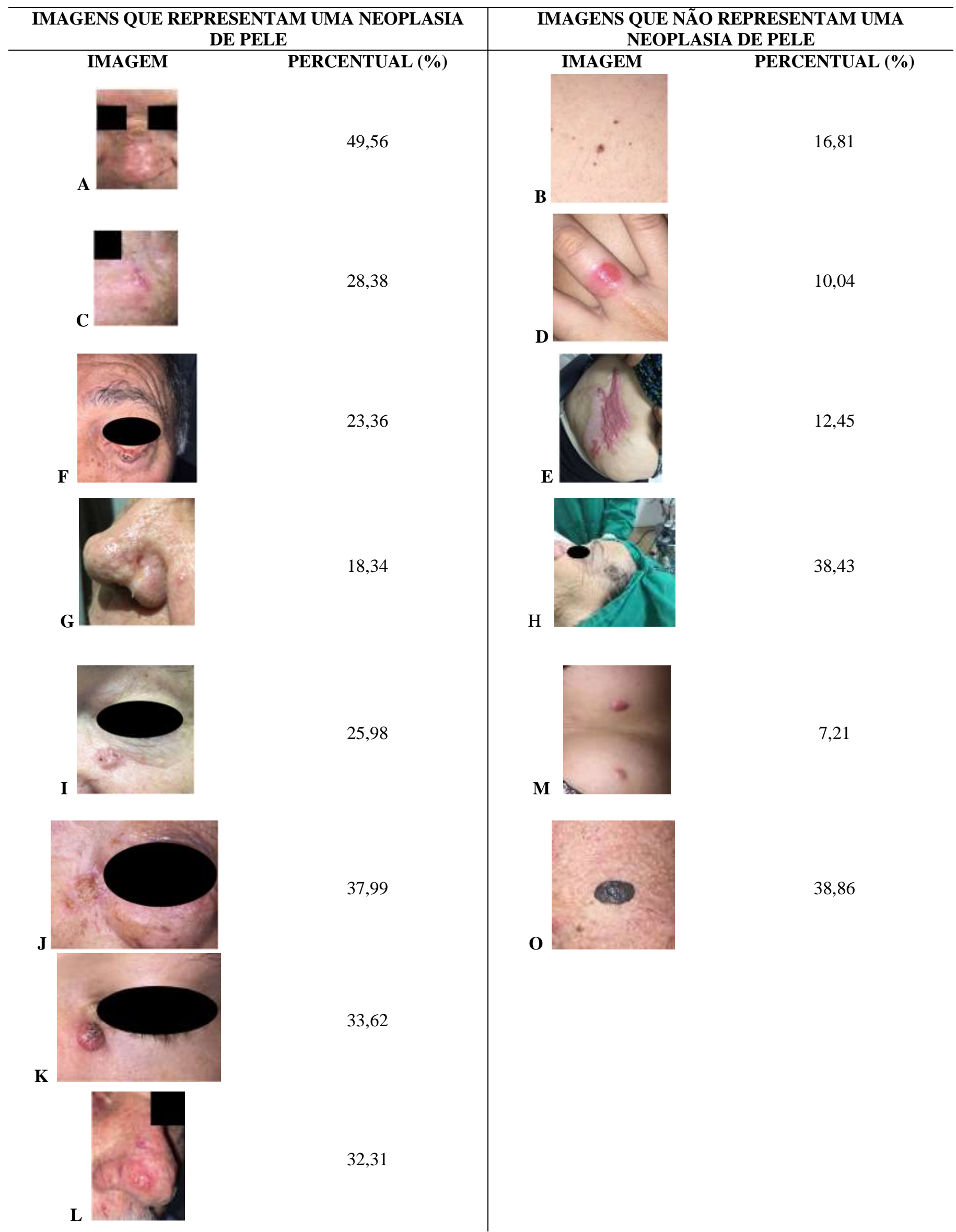


Fonte: Dados da pesquisa.

\subsection{Avaliação da relação do conhecimento sobre câncer de pele com variáveis demográficas}

Para o cálculo do escore de conhecimento de neoplasias de pele foram consideradas 10 questões, listadas a seguir, com suas respectivas respostas corretas: Q13) POSSIBILIDADE DE EXPOSIÇÃO AO SOL - Sim; Q15) PERIGO DO CÂNCER DE PELE - Sim; Q16) LETALIDADE DO CÂNCER DE PELE - Sim; Q17) MANIFESTAÇÕES CLÍNICAS Pápula, nódulos, tumores, úlceras, manchas pretas; Q18) SINAIS E SINTOMAS - Aumento de tamanho, mudança de cor, resistência ao tratamento, coceira, feridas que nunca cicatrizam, sangramento fácil; $\quad$ Q19) FATORES DE RISCO Exposição à radiação, cor da pele, idade - pessoas mais velhas, sexo - homens, fatores genéticos, produtos químicos, infecção, ter tido outro câncer de pele, tabagismo, imunodepressão; Q20) ENVOLVIMENTO DE MUCOSAS - Sim; Q21) METASTATIZAR - Sim. Q23) ITENS QUE DEVEM SER AVALIDOS - Assimetria, borda mal delimitada, cor, diâmetro, evolução, presença de pus ou sangue, elevação da pele; Q26) IMAGENS - a, c, f, g, i, j, k, 1, n.

Nesse sentido, as questões 13, 15, 16, 20 e 21, que admitiram apenas uma resposta, pontuaram 1 para os entrevistados que apontaram a alternativa correta e 0 para os que apontaram outra alternativa ou não responderam à questão. Levando em conta as questões 17, 18, 19, 23 e 26, que admitiram mais de uma resposta, para cada alternativa a pontuação foi obtida pela proporção de itens marcados (ou não marcados) corretamente, sendo assim, a pontuação de tais itens também varia de 0 a 1 .

$\mathrm{Na}$ análise estatística foi possível verificar que respondentes que obtiveram escores menores de 5 pontos, classificados com conhecimento baixo a respeito das neoplasias de pele, correspondeu a $41,70 \%$ dos entrevistados, enquanto aqueles que obtiveram 5 pontos ou mais foram classificados com alto conhecimento e correspondem a 58,30\% do total de participantes da pesquisa.

A distribuição de frequências dos fatores considerados, de acordo com a classificação do conhecimento sobre neoplasias de pele, assim como os resultados do teste de associação qui-quadrado $\left(\chi^{2}\right)$ e estimativas da OR bruta com seus respectivos valores p, obtidos através do ajuste de modelos logísticos univariados, estão dispostos na Tabela 4. Os resultados apresentados na Tabela 4 mostram que os estudantes da área da saúde apresentam chances significativamente maiores de apresentar um alto conhecimento sobre neoplasias de pele em comparados aos profissionais (OR de 3,38 e valor $\mathrm{p}<0,001)$. Com relação aos estudantes da área de humanas e exatas, percebe-se uma tendência ao baixo conhecimento (OR de 0,65 e 0,61 , respectivamente).

Também foi observado que entre os indivíduos classificados com baixo conhecimento sobre neoplasias de pele, menos de 30\% possuem renda familiar superior a 6 salários mínimos, enquanto essa porcentagem sobe para $47 \%$ entre os que possuem alto conhecimento. Sendo assim, as pessoas com renda familiar superior a 6 salários mínimos apresentaram melhor conhecimento do que as pessoas com renda inferior. Isso se expressa de modo mais significativo quando analisamos rendas superiores a 12 salários que apresentaram $\mathrm{p}<0,01$. 
Tabela 4. Análise univariada da classificação do conhecimento sobre neoplasias de pele em função de fatores em estudo e resultado do teste de associação qui-quadrado.

\begin{tabular}{|c|c|c|c|c|c|}
\hline \multirow{2}{*}{ Variável } & \multicolumn{2}{|c|}{ Conhecimento } & \multicolumn{2}{|c|}{ Odds ratio } & \multirow{2}{*}{$\begin{array}{l}\text { Teste } \chi^{2} \\
\text { Valor } \mathbf{p}\end{array}$} \\
\hline & Baixo & Alto & Bruta & Valor $\mathbf{p}$ & \\
\hline Curso & & & & & $<0,001 *$ \\
\hline Profissionais & $77(40 \%)$ & $81(30 \%)$ & 1 & - & \\
\hline Saúde & $38(20 \%)$ & $135(51 \%)$ & 3,38 & $<0,001 *$ & \\
\hline Exatas & $45(24 \%)$ & $31(12 \%)$ & 0,65 & 0,134 & \\
\hline Humanas & $31(16 \%)$ & $20(7 \%)$ & 0,61 & 0,136 & \\
\hline Sexo & & & & & 0,466 \\
\hline Feminino & $113(59 \%)$ & $171(64 \%)$ & 1,00 & - & \\
\hline Masculino & $78(41 \%)$ & $96(36 \%)$ & 0,81 & 0,289 & \\
\hline Idade & & & & & 0,466 \\
\hline 18-25 anos & $130(68 \%)$ & $184(69 \%)$ & 1,00 & - & \\
\hline 26-31 anos & $25(13 \%)$ & $39(15 \%)$ & 1,10 & 0,729 & \\
\hline 31-36 anos & $13(7 \%)$ & $24(9 \%)$ & 1,30 & 0,464 & \\
\hline $37-42$ anos & $12(6 \%)$ & $12(4 \%)$ & 0,71 & 0,413 & \\
\hline 42-60 anos & $11(6 \%)$ & $8(3 \%)$ & 0,51 & 0,164 & \\
\hline Estado civil & & & & & 0,825 \\
\hline Solteiro(a) & $145(76 \%)$ & $203(76 \%)$ & 1,00 & - & \\
\hline Casado(a) & $34(18 \%)$ & $49(18 \%)$ & 1,03 & 0,907 & \\
\hline Com companheiro(a) & $11(6 \%)$ & $13(5 \%)$ & 0,84 & 0,689 & \\
\hline Viúvo(a) & $0(0 \%)$ & $1(0 \%)$ & - & - & \\
\hline Nível Educacional & & & & & 0,775 \\
\hline Ensino médio incompleto & $1(1 \%)$ & $1(0 \%)$ & 1,00 & - & \\
\hline Ensino médio completo & $11(6 \%)$ & $16(6 \%)$ & 1,45 & 0,798 & \\
\hline Superior incompleto & $123(64 \%)$ & $173(65 \%)$ & 1,41 & 0,810 & \\
\hline Superior completo & $42(22 \%)$ & $50(19 \%)$ & 1,19 & 0,903 & \\
\hline Mestrado & $13(7 \%)$ & $26(10 \%)$ & 2,00 & 0,634 & \\
\hline Renda Familiar & & & & & $<0,001 *$ \\
\hline Nenhuma ou até 1 salário mínimo & $20(10 \%)$ & $16(6 \%)$ & 1,00 & - & \\
\hline De 1 a 3 salários mínimos & $57(30 \%)$ & $44(16 \%)$ & 0,96 & 0,927 & \\
\hline De 3 a 6 salários mínimos & $60(31 \%)$ & $70(26 \%)$ & 1,46 & 0,319 & \\
\hline De 6 a 9 salários mínimos & $19(10 \%)$ & $38(14 \%)$ & 2,50 & $0,036^{*}$ & \\
\hline De 9 a 12 salários mínimos & $19(10 \%)$ & $28(10 \%)$ & 1,84 & 0,173 & \\
\hline De 12 a 15 salários mínimos & $6(3 \%)$ & $36(13 \%)$ & 7,50 & $<0,001 *$ & \\
\hline Mais de 15 salários mínimos & $8(4 \%)$ & $27(10 \%)$ & 4,22 & $0,006^{*}$ & \\
\hline Fototipo de Pele & & & & & 0,052 \\
\hline Fototipo 1 & $21(11 \%)$ & $31(12 \%)$ & 1,00 & - & \\
\hline Fototipo 2 & $70(37 \%)$ & $107(40 \%)$ & 1,04 & 0,914 & \\
\hline Fototipo 3 & $74(39 \%)$ & $75(28 \%)$ & 0,69 & 0,250 & \\
\hline Fototipo 4 & $19(10 \%)$ & $47(18 \%)$ & 1,68 & 0,188 & \\
\hline Fototipo 5 & $6(3 \%)$ & $5(2 \%)$ & 0,56 & 0,392 & \\
\hline Fototipo 6 & $0(0 \%)$ & $2(1 \%)$ & - & - & \\
\hline $\begin{array}{l}\text { Conhece alguém que tem ou teve } \\
\text { câncer de pele }\end{array}$ & & & & & 0,542 \\
\hline Não & $101(53 \%)$ & $133(50 \%)$ & 1,00 & - & \\
\hline Sim & $89(47 \%)$ & $134(50 \%)$ & 1,14 & 0,481 & \\
\hline
\end{tabular}

* valor $\mathrm{p}<0,05$. Fonte: Dados da pesquisa. 
Apenas as variáveis curso e renda familiar mostraram evidências amostrais suficientes de associação significativa com a classificação do conhecimento sobre neoplasias de pele, ao nível de 5\% de significância, sendo que além dessas, a variável fototipo de pele também foi incluída no modelo múltiplo por apresentar associação moderada, com valor p menor que 0,25.

Em sequência, uma análise multivariada foi realizada com o objetivo de avaliar possíveis correlações para aquelas variáveis que apresentaram associação ao menos moderada $(\mathrm{p}<0,25)$ com a variável que indica conhecimento bom pelo teste qui-quadrado. A Tabela 5 apresenta os resultados das estimativas da razão de chances (OR ajustada), com seus respectivos intervalos de 95\% de confiança e valores p, obtidos através do ajuste de um modelo logístico múltiplo.

Como pode ser visto na Tabela 5, ser estudante da área da saúde (OR de 2,45 e valor p < 0,001), assim como possuir renda familiar de 12 a 15 ou de mais de 15 salários mínimos (ORs de 5,78 e 3,33 e valores p de 0,003 e 0,032) mantiveram-se como fatores que aumentam as chances de se obter uma classificação alta do conhecimento sobre neoplasias de pele em relação às suas respectivas bases de comparação.

Ainda, observa-se que os alunos dos cursos de exatas apresentaram chances significativamente menores, cerca da metade, de apresentar um alto conhecimento de neoplasias de pele em relação aos profissionais (OR de 0,54 e valor p de 0,040), ao nível de 5\% de significância.

Tabela 5. Análise multivariada da classificação do conhecimento sobre neoplasias de pele em função de fatores em estudo.

\begin{tabular}{lcc}
\hline & & Odds ratio \\
Variável & Ajustada & Valor p \\
Curso & & - \\
Profissionais & 1 & $<0,001^{*}$ \\
Saúde & 2,45 & $0,040^{*}$ \\
Exatas & 0,54 & 0,113 \\
Humanas & 0,58 & - \\
Renda familiar & & 0,797 \\
Nenhuma ou até 1 salário mínimo & 1 & 0,182 \\
De 1 a 3 salários mínimos & 1,11 & 0,056 \\
De 3 a 6 salários mínimos & 1,72 & 0,209 \\
De 6 a 9 salários mínimos & 2,44 & $0,003 *$ \\
De 9 a 12 salários mínimos & 1,82 & $0,032^{*}$ \\
De 12 a 15 salários mínimos & 5,78 & - \\
Mais de 15 salários mínimos & 3,33 & 0,957 \\
Fototipo de Pele & & 0,125 \\
Fototipo 1 & 1 & 0,158 \\
Fototipo 2 & 0,98 & 0,949 \\
Fototipo 3 & 0,58 & - \\
Fototipo 4 & 1,83 & \\
Fototipo 5 & 1,02 & \\
Fototipo 6 & - & \\
\hline
\end{tabular}

* valor $\mathrm{p}<0,05$. Fonte: Dados da pesquisa.

\section{Discussão}

O Brasil é um país popularmente miscigenado, com uma heterogeneidade de climas e extensas dimensões continentais, sendo quase a totalidade de seu território localizado entre a Linha do Equador e o Trópico de Capricórnio (maior 
proximidade com o Sol), o que o torna um dos países que, mundialmente, apresentam temperaturas mais elevadas e maior incidência de radiação ultravioleta. Tais fatos são fatores que corroboram para a elevada ocorrência de neoplasias de pele, e, portanto, sua população requer maior acesso às informações preventivas e de autocuidado para impedir o desenvolvimento da doença ou pelo menos promover o seu diagnóstico de forma precoce. Nesse sentido, estudos que ratifiquem o conhecimento da população acerca dessa neoplasia, abordando suas principais características, são de extrema relevância para permitir como a difusão e as ações de informação podem ser viabilizadas à população.

Os dados obtidos neste estudo evidenciaram que a maioria $(58,30 \%)$ dos participantes apresentaram um bom conhecimento relacionado aos aspectos gerais do câncer de pele. Em contrapartida, outros estudos, relacionados ao conhecimento populacional sobre as neoplasias de pele, revelaram que nas populações estudadas o conhecimento acerca da doença foi moderado, ou seja, as pessoas apresentaram algum conhecimento sobre os malefícios e riscos relacionados ao câncer de pele, mas não colocaram em práticas medidas preventivas e de autocuidado, sobretudo, em relação à fotoexposição (Castilho et al., 2010; Turco, 2010).

O bom conhecimento avaliado no estudo foi positivamente relacionado com duas variáveis sociodemográficas. Em primeiro lugar a área de estudo dos participantes - saúde e em segundo, a renda familiar superior a 6 salários mínimos. Tal relação se justifica pelo fato de as duas variáveis possibilitarem maior acesso às informações sobre a doença, seus riscos e o meio de preveni-los. Quando comparados aos acadêmicos de exatas ou humanas, os estudantes da área da saúde mantiveram conhecimentos mais elevados em relação ao câncer de pele, o que já era esperado, como Castilho, et al. (2010) observou em seu estudo a mesma correlação. Além disso, uma renda maior permite acesso aos equipamentos de proteção, como filtro solar, óculos, bonés, roupas térmicas, entre outros, que exigem um custo que muitas vezes pode ser elevado.

Apesar da relação entre renda e maior facilidade de compra de equipamentos e produtos de proteção, às práticas preventivas revelaram-se pouco difundidas no nosso estudo, como foi mostrado em relação à aplicação do protetor solar cujo uso não ocorre na frequência e maneira correta. Em consonância, o estudo de Frighetto et al. (2018) sobre a análise do conhecimento sobre as neoplasias de pele em Agentes Comunitários de Saúde evidenciou que, apesar da maior parte de sua amostra realizar o uso diário do filtro solar, essa não o utiliza de forma correta. O mesmo também foi observado no estudo de Castilho, et al. (2010) e colaboradores, relativo ao conhecimento sobre fotoexposição e fatores de risco do câncer de pele em estudantes universitários, o qual observou que tanto homens, quanto mulheres faziam o uso na frequência inadequada do filtro solar. Nota-se, portanto, que parece haver, por parte da população, um desconhecimento em relação ao uso correto do filtro solar como forma de prevenção do câncer de pele e outras complicações cutâneas. Como essa é uma das principais medidas individuais de proteção à radiação, campanhas de promoção deveriam ser implementadas pelo sistema de saúde, já que o uso adequado do filtro solar (uso diário com reaplicação a cada 2-3h) inibe a passagem da radiação ultravioleta.

Sobre a possibilidade de exposição ao sol sem que seja prejudicial à saúde, em horário de elevada radiação, 64,85\% dos entrevistados afirmaram não haver essa chance, o que evidencia que poucos foram os indivíduos que conhecem essa possibilidade quando se trata de adquirir vitamina D. No entanto, é importante considerar que a SBD recomenda que a exposição ao sol, para esse fim, seja feita em áreas cobertas que apresentem menor exposição diária, tais como costas, barriga, palmas e plantas, por 5 a 10 minutos diários, preconizando que se conheçam os níveis individuais de vitamina $\mathrm{D}$ e que a reposição oral seja feita com acompanhamento médico. Todavia, mesmo diante dos benefícios da vitamina $\mathrm{D}$, a SBD ainda incentiva a população a evitar a exposição solar sem proteção adequada, especialmente em horários de maior risco (entre as 10 e 16 horas) (SBD, 2013).

Em relação ao conhecimento acerca das neoplasias de pele e a sua gravidade, nosso estudo comprovou o que já vem sendo elucidado na literatura. Observou-se que quase a totalidade dos entrevistados já ouviram falar sobre as neoplasias de pele e a maior parte $(93,89 \%)$ afirmaram que ele é perigoso e pode até levar ao óbito. Isso evidencia que a maioria das pessoas que 
o conhecem sabem da sua magnitude e risco à saúde, pois para elas a palavra câncer está naturalmente associada à doença grave que, em grande parte das vezes, pode levar o paciente ao óbito. Todavia, tal relação constitui, segundo Bertolini (2009), um dos mitos e barreiras que devem ser enfrentados para prevenir e alterar a atual situação do câncer no país.

A respeito das manifestações clínicas, as pápulas, os nódulos, os tumores, as úlceras e as manchas pretas podem se tornar lesões cutâneas cancerígenas porque são dermatologicamente definidas como lesões elementares, ou seja, padrões de alteração do tegumento que podem ser desencadeadas por processos inflamatórios, degenerativos, circulatórios, metabólicos e neoplásicos. Com relação ao conhecimento acerca dessas manifestações, dado interessante é encontrado quando se compara o presente estudo com o artigo de Kelati et al. (2017). Em uma pesquisa realizada no Marrocos, o trabalho desses autores evidenciou como inferior o percentual de indivíduos que assinalaram as manchas pretas como manifestação característica do câncer de pele se comparado ao presente estudo (2,9\% x 64,41\%), no entanto, pápulas, nódulos, tumores e bolhas com pus apresentaram percentual semelhante entre os dois estudos. Tendo em vista esse contexto, o presente trabalho indicou que a população entrevistada apresentou bom conhecimento relacionado às manifestações clínicas.

Por outro lado, é importante discutir com a população sobre a conduta a ser tomada mediante a identificação dessa manifestação, isso porque nem sempre a busca por atendimento médico é realizada. O INCA, em seu arquivo sobre monitoramento das ações de controle do câncer de pele, evidenciou que apesar de não haver estudos sobre diminuição da morbimortalidade pelo autoexame da pele, há estudos que indicam que o autoconhecimento sobre essa, a prudência em relação às possíveis alterações relacionadas a ela e a sensibilização de pessoas de maior risco possibilitam que sejam identificadas lesões suspeitas e que, assim um diagnóstico de câncer de pele poderia ser realizado de forma mais precoce por um médico, o que poderia acarretar um melhor prognóstico para o paciente (Instituto Nacional do Câncer [INCA], 2016).

Quanto aos sinais e sintomas característicos das neoplasias de pele, embora aumento de tamanho, mudança de cor e feridas que nunca cicatrizam tenha sido corretamente marcadas pela maioria dos entrevistados em nosso estudo, maior conhecimento deve ser proporcionado à população. Isso, pois, resistência ao tratamento usual (sem melhora), coceira e sangramento fácil também são manifestações importantes e frequentes da doença e um percentual menor de entrevistados marcaram-nos (INCA, 2016). O mesmo ocorreu em relação aos fatores de risco, para os quais deve ser realizada a expansão de ações de conhecimento, em especial para imunodepressão e tabagismo, que foram pouco ressaltados pelos entrevistados e são de extrema importância para predispor uma neoplasia de pele (Grupo Brasileiro de Melanoma, 2019). Todavia, os entrevistados tinham conhecimento sobre a exposição à radiação $(97,38 \%)$, fatores genéticos $(72,05 \%)$ e cor da pele $(56,33 \%)$, que são os fatores predominantes para a ocorrência da neoplasia.

A exposição à radiação ultravioleta induz a carcinogênese, pois causa danos cumulativos ao DNA das células do tecido cutâneo (Lopes et al., 2017). Um dos danos mais evidentes é a alteração do gene TP53, que é um supressor tumoral responsável por regular o processo de divisão celular, reparando danos ao DNA e apoptose celular (Frighetto et al., 2018). Portanto, quando alterado, permite a multiplicação celular desenfreada, que é a principal característica carcinogênica. Com base nisso, os fatores genéticos, são relevantes nos casos de melanoma hereditário, no qual a mutação do gene CDKN2A está presente. Esse gene é responsável por codificar a proteína P16, que inibe um grupo de enzimas denominadas Cinases dependentes de Ciclinas (CDKs), que participam da proliferação celular (Frighetto et al., 2018).

Castilho et al. (2010), em seu estudo sobre fotoexposição e fatores de risco para o câncer de pele em estudantes universitários, legitimaram o que evidenciamos em nosso estudo. $\mathrm{O}$ trabalho mostrou que a maior parte dos acadêmicos apresentaram a percepção da radiação ultravioleta como fator de risco para as neoplasias de pele, bem como da influência genética na doença. Porém, um dado curioso observado foi a comparação entre a área de saúde e área de humanas, em que houve discrepância significativa. Enquanto $72 \%$ de acadêmicos da saúde acham que o fator genético é um fator de risco para as neoplasias de pele, $86 \%$ dos acadêmicos de humanas não consideram essa variável relevante. Tal discrepância não foi 
observada no nosso estudo, no qual aproximadamente $86 \%$ dos acadêmicos das duas áreas indicaram fator genético como fator de risco (Dados não mostrados). Este é um ponto que deve ser evidenciado, pois, se um indivíduo apresenta características genéticas que favoreçam a ocorrência de neoplasias de pele ou apresenta histórico familiar deste câncer, a ausência de sintomas ou a não investigação de determinada lesão elementar que pode tornar-se cancerígena pode retardar a procura médica e, consequentemente, dificultar um diagnóstico e tratamento precoces. Cezar-vaz et al. (2015), em seu estudo sobre o câncer de pele em trabalhadores rurais, evidenciaram que entre aqueles que tiveram diagnóstico de câncer de pele, apenas 28,6\% não sabiam seu histórico familiar, enquanto 71,4\% tinham conhecimento sobre o seu histórico familiar.

Em relação às mucosas, observou-se que a maioria dos entrevistados não sabiam se essas poderiam ser acometidas pelo câncer de pele (42,58\%). Lima et al. (2009) afirmaram que o envolvimento de mucosas pode ocorrer, embora seja em menor proporção (1,3\% dos melanomas). Para as metástases, 58,30\% afirmaram que elas podem ocorrer (a maioria dos entrevistados ressaltaram que os principais órgãos passíveis de serem metastizados são pulmão, ossos e linfonodos) e 37,77\% não souberam responder à pergunta. Dimatos et al. (2009), em seu artigo, ressaltaram que não só pulmão, ossos, linfonodos, mas também fígado e cérebro são outros locais propensos a sofrerem metástases de uma neoplasia de pele e Carneiro et al. (2010) destacaram ainda que, embora raro, o câncer no trato gastrointestinal também pode ser metástase do câncer de pele. Tal fato reforça que também há um desconhecimento da população em relação a essas características, uma vez que a maior parte dos indivíduos associam a neoplasia de pele como algo externo, ligada diretamente à superfície cutânea de alguma região do corpo (devido justamente à radiação ultravioleta), contudo ela pode atingir regiões internas e geralmente é indicativa de mau prognóstico (Carneiro et al., 2010).

Uma das maneiras de avaliar uma lesão elementar e investigar se ela pode ou não ser indicativa de uma neoplasia de pele é através de uma regra mnemônica fácil e simples cujo conhecimento pode ser utilizado por qualquer indivíduo. Tal regra, denominada $\mathrm{ABCDE}$ do câncer de pele, avalia as particularidades de uma lesão cutânea neoplásica analisando: A (Assimetria), B (Bordas), C (Coloração), D (Diâmetro) e E (Evolução) da lesão (Sociedade Brasileira de Dermatologia [SBD], 2017). Dessa forma, lesões que se apresentam assimétricas, com bordas elevadas e não planas, com uma variedade de cores, geralmente de diâmetro maior que $5 \mathrm{~mm}$ e que evoluem ao longo do tempo, mesmo que de forma lenta, são altamente sugestivas de câncer de pele e, nesses casos, a procura de assistência médica é mandatória (INCA, 2020). Porém, essa regra aplica-se apenas ao câncer de pele do tipo melanoma, sendo que para o câncer de pele do tipo não melanoma, as lesões geralmente são pruriginosas, descamativas ou sangram, alteram de tamanho, forma ou cor, e a ferida existente não cicatriza em 4 semanas (INCA, 2020). No presente estudo, não só quase a totalidade dos entrevistados afirmaram não conhecerem sobre a regra do ABCDE do câncer de pele, mas também, dos que se mostraram conhecedores, 52,78\% afirmaram que ela aplica apenas ao tipo Melanoma e um número aproximado afirmou que essa se aplica a ambos os tipos de cânceres de pele. Isso evidencia que, dos que conhecem sobre o mnemônico, esses sabem-no de forma incorreta, ratificando a desinformação da população e, consequente necessidade de informá-los e capacitá-los com relação às ações que permitam a identificação e diagnóstico precoces da doença.

Apesar de o aspecto da lesão não poder ser considerado isoladamente no diagnóstico do câncer de pele, foi muito interessante observar a percepção dos entrevistados diante de lesões das quais eles tiveram que sinalizar se seriam ou não cancerígenas. De modo geral, a maioria dos entrevistados reconheceram uma lesão cancerígena cutânea (A, C, F, G, I, J, K, L e $\mathrm{N}$ são as lesões cancerígenas, sendo $\mathrm{A}$ e $\mathrm{N}$ as lesões mais assinaladas). No entanto, duas imagens que não caracterizam neoplasia $(\mathrm{O}$ e $\mathrm{H})$ foram altamente assinaladas pelos entrevistados. Tais imagens podem ter sido demarcadas pelos entrevistados, pois podem ser altamente confundidas com o melanoma, devido a sua coloração enegrecida e sua localização em área de fotoexposição.

Entende-se, portanto, que ações informativas à população em geral, que contemplem esclarecimentos e orientações tanto em relação às medidas protetivas, sobretudo em relação à fotoproteção, quanto em relação à própria doença em si, 
abordando fatores de risco e manifestações clínicas são de extrema importância no que toca à identificação das lesões e diagnóstico prévio.

\section{Conclusão}

O reconhecimento de sinais e sintomas das neoplasias de pele representam um desafio para a população, que, de forma geral, hesita em reconhecê-los e buscar auxílio e assistência médica quando necessário. Tal fato decorre do nãoconhecimento e da escassez das informações difundidas que levam a população a atentar-se para as particularidades da doença, já que muitas vezes a apresentação clínica, os sinais e sintomas das neoplasias de pele são inespecíficos e facilmente confundidos com outras lesões elementares. As principais manifestações clínicas (regra do ABCDE), bem como fatores de risco, os sinais e sintomas da doença deixaram algumas dúvidas nos entrevistados, notando-se que muitos não dispunham de compreensão de algumas dessas características. Além disso, apesar de o estudo evidenciar que a população tem conhecimento sobre a malignidade e letalidade da doença, as práticas preventivas são pouco difundidas, como foi mostrado no estudo em relação à aplicação do protetor solar cujo uso não ocorreu na frequência e maneira corretas. Dessa forma, o estudo evidenciou que, apesar de haver elevada importância de maiores ações de promoção de informação acerca das neoplasias cutâneas, há uma enorme necessidade de se colocar em prática ações que estimulem mudanças de comportamento. Portanto, estratégias de difusão de informação, sobretudo através das mídias sociais, centros acadêmicos, murais em Unidades Básicas de Saúde e centros médicos, a fim de atender a população e sanar suas dúvidas em relação às neoplasias de pele e formas de preveni-la, são de extrema importância e devem ser encorajados e desenvolvidos, o que corrobora para o diagnóstico precoce e melhor prognóstico da doença.

\section{Referências}

Bertolini, W. L. H. M. (2009). A influência do D-limoneno como promotor de absorção de ácido 5 -aminolevulínico para Terapia Fotodinâmica do câncer de pele: avaliação in vitro e in vivo da permeação e retenção cutâneas. Tese de Doutorado, Faculdade de Ciências Farmacêuticas de Ribeirão Preto, Universidade de São Paulo, Ribeirão Preto. 10.11606/T.60.2009.tde-12052009-191324. Recuperado de www.teses.usp.br

Carneiro, J. Q., Landim, M. R., Mendes, J. V. S., Landim, M. R., \& Pinho, A. S. (2010). Melanoma gástrico metastático: Relato de caso. Revista Brasileira de Clínica Médica, 8(5), 461-463. http://files.bvs.br/upload/S/1679-1010/2010/v8n5/017.pdf

Castilho, I. G., Sousa, M. A. A., \& Leite, R. M. S. (2010). Fotoexposição e fatores de risco para câncer da pele: uma avaliação de hábitos e conhecimentos entre estudantes universitários. Anais Brasileiros de Dermatologia, 85(2), 173-178. https://dx.doi.org/10.1590/S0365-05962010000200007

Cezar-Vaz, M. E., Bonow, C. A., Piexak, D. R., Kowalczyk, S., Cezar-Vaz J. \& Borges A. M. (2015). Câncer de pele em trabalho rural: conhecimento e intervenção de enfermagem. Revista da Escola de Enfermagem da USP, 49 (4), 0564-0571. https://doi.org/10.1590/S0080-623420150000400005

Dimatos, D. C., Duarte F. O., Machado, R. S., Vieira, V. J., Vasconcellos, Z. A. A., Bins-ely, J., \& Neves, R. D. (2009). Melanoma cutâneo no Brasil. Arquivos Catarinenses de Medicina, 38(1), 14-19. http://www.acm.org.br/acm/revista/pdf/artigos/637.pdf

Favalli, P., Bergonsi, T. O., Pavanello, D. P., Orsi, V., Pase, P., Schimidt, M., \& Silva, J. B. (2007). Carcinoma Epidermoide de pele: aspectos clínicopatológicos e sociais, Revista da AMIRGS, 51(4), 301-305.

Frighetto, A. V., Schmidt, R. B., Jacomeli, M. D., \& Millam, W. C. (2018). Câncer de Pele: Avaliação, conhecimento e identificação em agentes comunitários de saúde no município de Ji-Paraná-RO. Brazilian Journal of Surgery and Clinical Research - BJSCR, 25(2), 38-42. https://www.mastereditora.com.br/periodico/20190103_215127.pdf

Grupo Brasileiro de Melanoma. (2019). Cartilha de Tratamento CEC de pele. https://gbm.org.br/wp-content/uploads/2019/09/livreto-GBM-v2.pdf.

Instituto nacional do câncer. (2016). Monitoramento das Ações de Controle do Câncer de Pele. 7(3). https://www.inca.gov.br/sites/ufu.sti.inca.local/files/media/document/informativo-deteccao-precoce-3-2016.pdf

Instituto Nacional do Câncer. (2020). Câncer de pele não melanoma. Rio de Janeiro. https://www.inca.gov.br/tipos-de-cancer/cancer-de-pele-nao-melanoma.

Instituto Nacional do Câncer. (2019). Estimativa 2020: Incidência de câncer no Brasil. https://www.inca.gov.br/sites/ufu.sti.inca.local/fi les/media/document/estimativa-2020-incidencia-de-cancer-no-brasil.pdf.

Instituto Nacional do Câncer. (2018). Exposição no trabalho e no ambiente. https://www.inca.gov.br/EXPOSICAO-NO-TRABALHO-E-NO-AMBIENTE.

Instituto Nacional do Câncer. (2020). Câncer de pele melanoma. https://www.inca.gov.br/tipos-de-cancer/cancer-de-pele-melanoma. 
Research, Society and Development, v. 10, n. 5, e36210515038, 2021

(CC BY 4.0) | ISSN 2525-3409 | DOI: http://dx.doi.org/10.33448/rsd-v10i5.15038

Iranzo, C. C., Rubia-Orti, J. E. L., Castillo, S. S., \& Firmino-Canhoto, J. (2015). Lesões cutâneas malignas e pré-malignas: conhecimentos, hábitos e campanhas de proteção solar. Acta Paulista de Enfermagem, 28 (1), 2-6. https://dx.doi.org/10.1590/1982-0194201500002

Kelati, A., Baybay, H., Atassi, M., Elfakir, S., Gallouj, S., Meziane, M., \& Mernissi, F. Z. (2017). Skin cancer knowledge and attitudes in the region of Fez, Morocco: a cross-sectional study. BMC dermatology, 17(1), 2. https://doi.org/10.1186/s12895-017-0055-8

Lima, R. L. F., Nóbrega, M. Q. R., Moraes, M. L. S. A., Miguel, M. C. C., Lima, K. C. \& Silveira, E. J. D. (2009). Estudo retrospectivo de melanomas cutâneos e mucosos na população do estado do Rio Grande do Norte, Brasil. Jornal Brasileiro de Patologia e Medicina Laboratorial, 45(6), 493-499. https://dx.doi.org/10.1590/S1676-24442009000600009

Lopes, L. G., Sousa, C. F. \& Libera, L. S. D. (2018). Efeitos biológicos da radiação ultravioleta e seu papel na carcinogênese de pele: uma revisão. Revista Eletrônica da Faculdade Evangélica de Ceres, 7(1), 117-146. http://periodicos.unievangelica.edu.br/index.php/refacer/article/view/3327

Matheus, L. G. M. \& Verri, B. H. M. A. (2015). Aspectos epidemiológicos do melanoma cutâneo. Revista Ciência e Estudos Acadêmicos de Medicina, 3(3), 10-24. https://periodicos.unemat.br/index.php/revistamedicina/article/view/625

Sociedade Brasileira de Dermatologia (SBD). (2013). Consenso Brasileiro de Fotoproteção. https://issuu.com/sbd.br/docs/consensob.fot oprote oleigoweb? $=0 / 6449812$.

Sociedade Brasileira de Dermatologia (SBD). (2017) Câncer de Pele. https://www.sbd.org.br/dermatologia/pele/doencas-e-problemas/cancer-da-pele/64/

Tovo, L. F. R., Festa, N. C., Castro, C. V. B. \& Sampaio, S. A. P. (2002). Carcinoma Basocelular, Sociedade Brasileira de Dermatologia, Projeto Diretrizes $A M B$ e CFM, p. 1-16. https://diretrizes.amb.org.br/_BibliotecaAntiga/carcinoma-basocelular.pdf

Turco, I. G. S. L. (2011). Avaliação do conhecimento quanto ao câncer de pele e sua relação com exposição solar em alunos do Senac de aparecida de Goiânia. Revista Brasileira De Geografia Médica E Da Saúde, 6(11). Recuperado de http://www.seer.ufu.br/index.php/hygeia/article/view/16997

World Health Organization (WHO). (2018). Fact Sheets. http://www.who.int/mediacentre/factsheets/fs297/en/.

World Health Organization (WHO). (2012). International Agency for Research on Cancer (GLOBOCAN 2012), Global Cancer Observatory (GC), Cancer Tomorrow and Predictions for all cancers except non-melanoma skin in 2025 and 2035. http://gco.iarc.fr/. 